\title{
Atividade anti-ixodídica dos fungos Sporothrix insectorum e Paecilomyces fumosoroseus sobre Boophilus microplus (Canestrini, 1887): bioensaios e microscopia eletrônica de varredura

\author{
The use of Sporothrix insectorum and Paecilomyces fumosoroseus against \\ Boophilus microplus (Canestrini, 1887): in vitro assay and electronic microscopy
}

\author{
Tiago Lot da Silva Nunes"; Érika Barbosa Neves Graminha'; Arlete Silveira Maia'; \\ Giane Serafim da Silva ${ }^{1,2}$; Nancy Prette Varandas ${ }^{1}$; Alvimar José da Costa ${ }^{1}$
}

\begin{abstract}
Resumo: Em função do desenvolvimento de resistência aos diversos quimioterápicos existentes, o controle biológico vem sendo uma alternativa promissora no controle do Boophilus microplus. Neste trabalho foi avaliada a ação patogênica de Sporothrix insectorum e de Paecilomyces fumosoroseus nas diferentes fases do ciclo de vida do Boophilus microplus. Para isso, os fungos em estudo foram cultivados em meio de cultura apropriado, obtendo-se a suspensão estoque, a partir da qual foram preparadas suspensões nas concentrações de $10^{5}$, $10^{6}, 10^{7}, 10^{8}, 10^{9}$ conídios/mL para ambos os fungos. Os ovos e as larvas foram tratados por aspersão, e as partenóginas foram imersas nas diferentes suspensões de conídios. A patogenicidade dos fungos foi avaliada pela "performance reprodutiva" das carrapatas. O delineamento experimental foi realizado com cinco repetições para cada grupo de tratamento, nas diferentes concentrações fúngicas. Os fungos $S$. insectorum e P. fumosoroseus reduziram em $50,19 \%$ e 49,34\%, respectivamente, a postura das partenóginas, quando utilizados na concentração de $10^{8}$ conídios $/ \mathrm{mL}$. Em relação à eficácia, tais fungos alcançaram os valores de $82,99 \%$ e $82,93 \%$ na concentração de $10^{8}$ conídios $/ \mathrm{mL}$ e na de $10^{9}$ conídios $/ \mathrm{mL}$, respectivamente. Sobre ovos de $B$. microplus, a atividade de $P$. fumosoroseus foi superior a de $S$. insectorum, reduzindo a eclodibilidade em $79,04 \%$ na concentração de $10^{6}$ conídios $/ \mathrm{mL}$. S. insectorum reduziu tal parâmetro em apenas $37,92 \%$, na concentração de $10^{7} \mathrm{conídios} / \mathrm{mL}$. No tratamento das larvas, os fungos avaliados não diferiram significativamente $(P<0,05)$ quanto à mortalidade das mesmas. As elétron-micrografias de varreduras, dos diferentes ínstares do B. microplus, evidenciam o poder predador dos fungos $S$. insectorum e $P$. fumosoroseus. Em face dos resultados obtidos, pode-se inferir que $S$. insectorum e $P$. fumosoroseus apresentaram ação deletéria sobre partenóginas de $B$. microplus in vitro, o que reforça a possibilidade do eventual emprego, desses fungos, no biocontrole desse importante ácaro.
\end{abstract}

Palavras-chave: Boophilus microplus, Sporothrix insectorum, Paecilomyces fumosoroseus, controle biológico.

\begin{abstract}
In function of the development resistance to the several existent quimiotherapics, biological control has being a promising alternative to the control of Boophilus microplus. In this work, the pathogenic action of Sporothrix insectorum and Paecilomyces fumosoroseus in the different stages of life cycle of Boophilus microplus was evaluated. The fungis in study were cultivated in appropriate culture medium and suspensions in the concentrations of $10^{5}, 10^{6}, 10^{7}, 10^{8}, 10^{9}$ conidia/mL for both fungis were prepared, starling from stock suspension. The eggs and the larvaes were treated by spray, and the engorged tick were immersed in the different conidia suspensions. The pathogenicity of the fungis were appraised for the reproductive performance of the ticks. The experimental was accomplished with five repetitions for each treatment group, in the different fungal concentrations. The fungis $S$. insectorum and $P$. fumosoroseus reduced in $50,19 \%$ and $49,34 \%$, respectively, the posture of the infected engorged female ticks, in the concentration $10^{8} \mathrm{conidia} / \mathrm{mL}$. In relation to effectiveness, the fungis $S$. insectorum and $P$. fumosoroseus, they reached the values $82,99 \%$, in the concentration $10^{8}$ conidia/mL, and $82,93 \%$ in the concentration $10^{9}$ conidia $/ \mathrm{mL}$, for the respective fungis. In the eggs treatment with the $S$. insectorum and $P$. fumosoroseus, the fungi $P$. fumosoroseus presented a superiority with reduction of eclodibility in $79,04 \%$, in the concentration $10^{6}$ conidia/mL, while the $S$. insectorum, reduced in only $37,92 \%$, in the concentration $10^{7}$ conidia/mL. In the larvas treatment there were not significant differences in the larva mortality in both fungi. The electronic microscopy, in different stage of life of the B. microplus, showed the power predatory of the fungi $S$. insectorum and $P$. fumosoroseus. With these results, it can be inferred that $S$. insectorum and $P$. fumosoroseus presented deleterious action on engorged female of $B$. microplus in vitro, what reinforces your possibility eventual control of this important tick.
\end{abstract}

Key words: Boophilus microplus, Sporothrix insectorum, Paecilomyces fumosoroseus, biologic control.

\footnotetext{
${ }^{1}$ CPPAR - Centro de Pesquisas em Sanidade Animal, FCAV/Unesp, Campus de Jaboticabal.

2 UNICASTELO - Universidade Camilo Castelo Branco - Campus VIII.
} 


\section{Introdução}

No Brasil, segundo Horn (1983), os prejuízos causados pelo Boophilus microplus atingem anualmente a cifra de um bilhão de dólares. Entre os fatores responsáveis por essas perdas destacam-se: desvalorização do couro pelo ataque direto do parasito, desgaste dos animais pelo hematofagismo a que são submetidos, irritação no local da picada, estresse pelo manejo imprimido aos animais para o controle do parasito, mortalidade de aproximadamente $1,2 \%$ do rebanho em virtude de intoxicações com antiparasitários, acidentes nos banheiros utilizados para o tratamento, redução da taxa de natalidade, alto custo de aquisição dos quimioterápicos, construção e manutenção de instalações, gastos com mão-de-obra, e principalmente transmissão dos agentes da Tristeza Parasitária Bovina (PENNA, 1990; VERRÍSSIMO, 1990).

O uso de produtos carrapaticidas é largamente difundido e empregado há anos, sendo considerado o principal método de controle dos carrapatos. Contudo, essa ampla utilização tem gerado a seleção de cepas resistentes, paralelamente ao aumento gradativo de custos quando aplicados isoladamente (DRUMOND, 1970, apud BARROS e EVANS, 1989).

O controle biológico tem se apresentado como uma alternativa promissora no controle de parasitos. Alguns fungos têm sido objeto de pesquisas para o controle alternativo de B. microplus. Rocha (1984) descreveu várias espécies de invertebrados que participam ativamente no controle da fase de vida livre de $B$. microplus.

Alves et al. (1993) verificaram que o Metarhizium anisopliae, nas doses $10^{6}$ e $10^{7}$ conídios $/ \mathrm{mL}$, impediu a eclosão total de ovos de B. microplus. Embora também patogênica para ovos desse ácaro, a Beauveria bassiana mostrou eficácia anti-embriogênica inferior o $M$. anisopliae. Porém, tais fungos foram avaliados apenas contra ovos de B. microplus.

O Sporothrix insectorum e o Paecilomyces fumosoroseus têm demonstrado efeitos satisfatórios quando utilizados na agricultura. Ordonez e David (1993) verificaram que o Sporothrix insectorum reduz acentuadamente a infestação pelo percevejo Leptopharsa heveae em seringueiras (Hevea brasiliensis). Ainda, o P. lilacinus, atuando em ovos de Meloidogyne arenaria, provocou uma diminuição do número deste parasito do solo, em estudo conduzido por Carlie e Watkinson (1994).

O Paecilomyces lilacinus, como parasito de ovos de nematóides do gênero Meloidogyne, é considerado bom agente de controle biológico. Giraldo e Leguizamom (1996) também estudaram o efeito de Paecilomyces spp. no controle de ovos de Meloidogyne spp. em raízes de diversas espécies de plantas cucurbitáceas. Os autores observaram que, após 100 dias, ocorreu uma redução significativa da porcentagem de infecção das raízes das referidas plantas pelo nematóide.

O presente trabalho teve como objetivo avaliar a atividade anti-ixodídica dos fungos Sporothrix insectorum e Paecilomyces fumosoroseus, em experimentos in vitro e por microscopia eletrônica de varredura, sobre as diferentes fases biológicas de Boophilus microplus (partenóginas, ovos e larvas).

\section{Material e Métodos \\ 2.1 Multiplicação e obtenção do inóculo}

Placas de Petri (BDA), contendo os S. insectorum e P. fumosoroseus, após 10 a 12 dias do cultivo, receberam, à temperatura ambiente, $5,0 \mathrm{~mL}$ de água destilada esterilizada. Com auxílio de uma alça de Drigalsky, os esporos foram removidos, sendo as suspensões transferidas para Erlenmeyers esterilizados com capacidade de $250 \mathrm{~mL}$, os quais foram estocados em geladeira a $4^{\circ} \mathrm{C}$. A partir dessas suspensões estoque, foram preparadas suspensões de esporos em água destilada e esterilizada, mais o espalhante Tween $80(1 \mathrm{~g} / 1 \mathrm{~L}$ de água), nas concentrações de $10^{5}, 10^{6}, 10^{7}, 10^{8} \mathrm{e} 10^{9}$ conídios/mL.

\subsection{Obtenção e axenização de partenóginas, de ovos e de larvas de $B$. microplus}

Os exemplares de B. microplus foram obtidos de animais naturalmente infestados. Parte das fêmeas ingurgitadas, colhidas e selecionadas após minucioso exame morfológico, foi empregada nos bioensaios in vitro e parte utilizada na manutenção da colônia de $B$. microplus. As fêmeas selecionadas foram axenizadas externamente, mergulhando-as em uma solução de hipoclorito de sódio a $0,5 \%$ por um minuto. Em seguida, foram transferidas para uma solução de tiossulfato de sódio a $1 \%$, por 30 segundos, e lavadas por três vezes consecutivas em água destilada esterilizada. Os exemplares colhidos e axenizados foram mantidos em placas apropriadas, em câmara climatizada (BOD), à temperatura de $27^{\circ} \mathrm{C}$, umidade relativa superior a $80 \%$ e fotoperíodo de 16 horas.

Após oviposição das carrapatas, os ovos foram pesados e distribuídos em placas de Petri, contendo ágar-água a $2 \%$, e previamente identificadas $(0,05 \mathrm{~g}$ de ovos por placa). Para obtenção de larvas, $0,05 \mathrm{~g}$ de ovos foram colocados em seringas esterilizadas adaptadas.

\subsection{Delineamento experimental}

Os testes foram realizados em duas etapas, com delineamento inteiramente casualizado, idênticos, para evitar contaminação cruzada entre os dois fungos. Em cada teste foram empregados cinco grupos tratamentos (concentrações fúngicas de $10^{5}, 10^{6}, 10^{7}, 10^{8}$ e $10^{9}$ conídios $/ \mathrm{mL}$ ), mais o grupo-controle, tratado apenas com o veículo das suspensões (água e uma gota de espalhante) e cinco repetições cada.

\subsection{Bioensaio - partenóginas}

As fêmeas ingurgitadas pertencentes às cinco repetições de cada tratamento (10 carrapatas por repe- 
tição), foram banhadas, por imersão, com $10 \mathrm{~mL}$ de cada suspensão ( $S$. insectorum ou $P$. fumosoroseus), durante cinco minutos. Em seguida, as carrapatas foram transferidas e fixadas individualmente em placas de Petri. Essas placas foram colocadas em condições favoráveis para o desenvolvimento do parasito e do patógeno em estufa tipo $\mathrm{BOD}, 27^{\circ} \mathrm{C}$, umidade superior a $80 \%$ e fotoperíodo de 16 horas, por um período de 20 dias.

\subsection{Bioensaio - ovos}

Os ovos utilizados nos testes foram colhidos de fêmeas axenizadas que ovipuseram em condições assépticas. A seguir, foram transferidos para placas de Petri, onde cada tratamento com cinco repetições foram tratados com duas gotas de suspensão de esporos de $S$. insectorum e/ou P. fumosoroseus (conta-gotas), nas diferentes concentrações utilizadas e acondicionados em câmara climatizada como descrito no item anterior.

\subsection{Bioensaio - larvas}

As larvas empregadas nos ensaios, provenientes de ovos das fêmeas axenizadas, foram colocadas em seringas esterilizadas até eclosão. Em seguida, alíquotas de larvas vivas e ativas foram transferidas para envelopes confeccionados com papel de filtro, os quais foram selados por grampos. Foram adicionadas aos mesmos duas gotas de suspensão das diferentes concentrações de $S$. insectorum e/ou $P$. fumosoroseus, sendo cada concentração acondicionada em placa de Petri e incubadas como descrito no item anterior. Os envelopes foram abertos cinco dias após o tratamento, tempo necessário à ação do fungo (ALVES et al., 1998).
A patogenicidade e reisolamento de $S$. insectorum e $P$. fumosoroseus, nos diferentes instares do $B$. microplus, após 25 dias do tratamento com as suspensões fúngicas foram avaliados e comparados com as culturas originais, segundo coloração e morfologia da colônia.

\subsection{Estudo ao microscópio eletrônico de varredura sobre o modo de ação de $S$. insectorum e $P$. fumosoroseus e mecanismo de parasitismo dos fungos sobre os diferentes instares do $B$. microplus}

Os ovos, as larvas e as partenóginas de $B$. microplus, após os respectivos períodos de incubação, foram examinados quanto à colonização pelos fungos. Os espécimens que se apresentaram parasitados foram fixados em glutaraldeído a 3\% em tampão de fosfato de potássio a 0,05 M, pH 7,4 por 72 horas. Em seguida, foram lavados na solução tampão pura, por seis vezes consecutivas, com intervalo de 15 minutos e fixados em tetróxido de ósmio a $2 \%$, no mesmo tampão. A seguir, foram novamente lavados, desidratados em uma série gradual de acetona, secos em secador de ponto crítico, montados em suportes, recobertos com $35 \mathrm{~nm}$ de ouro e elétron-micrografados em microscópio eletrônico de varredura JEOL JSM 5410, operando em 15 kV (MAIA E SANTOS, 1997).

\subsection{Parâmetros Ixodológicos}

Para a avaliação dos parâmetros ixodológicos, nos bioensaios com partenóginas, foi utilizada a equação (GONZALES et al., 1993):

$$
\begin{gathered}
\text { \% Redução de } \\
\begin{array}{c}
\text { oviposição } \\
\text { total }
\end{array}
\end{gathered}=\frac{\begin{array}{c}
\text { Peso médio da massa de } \\
\text { ovos do grupo controle }
\end{array}}{\text { Peso médio da massa de ovos do grupo controle }}
$$

Os percentuais de eclosão foram calculados por meio da contagem de cascas e ovos, oriundos de partenóginas e de ovos tratados, colhidas de todos os grupos e repetições experimentais.
A avaliação da redução do percentual de eclodibili-

\begin{tabular}{|c|c|c|c|c|}
\hline \multirow{2}{*}{$\begin{array}{l}\text { \% Percentual } \\
\text { Eclodibilidade }\end{array}$} & $\begin{array}{l}\text { Média da eclodibilidade } \\
\text { do grupo de controle }\end{array}$ & - & $\begin{array}{c}\text { Média da eclodibilidade } \\
\text { do grupo tratado }\end{array}$ & \multirow[t]{2}{*}{$\times 100$} \\
\hline & Média da eclodib & & do grupo controle & \\
\hline
\end{tabular}
dade dos ovos, submetidos ao $S$. insectorum e $P$. fumosoroseus, foi calculada da seguinte forma: 
A metodologia adotada para cálculo das percentagens de eficácia reprodutiva e de controle (eficácia) foi a estabelecida por Drummond et al. (1973), por meio das seguintes variáveis:

\begin{tabular}{|l}
$\begin{array}{l}\% \text { Estimativa de } \\
\text { Reprodução(ER) }\end{array}=\frac{\text { Peso dos ovos }(\mathrm{g})}{\text { Peso das fêmeas }(\mathrm{g})} \times \%$ Eclosão $\times 20000^{*}$ \\
$\%$ de Controle ou de eficácia $=\frac{\text { ER controle }- \text { ER tratado }}{\text { ER controle }} \times 100$
\end{tabular}

A mortalidade das larvas foi determinada à partir de exame através de estereoscópio e contato com estilete.

Os dados ixodológicos foram avaliados pelo procedimento ANOVA (SAS, 1998) e as médias comparadas pelo teste de Tukey.

\section{Resultados e Discussão}

Os resultados de redução de postura (Tabela 1) demonstraram que os fungos utilizados ( $S$. insectorume P. fumosoroseus) promoveram uma substancial redução na postura das partenóginas $(50,19 \%$ e $49,34 \%$, respectivamente), principalmente na concentração $10^{8}$ conídios/ $\mathrm{mL}$. Esses dados assemelham-se aos encontrados por Bittencourt (1992) que, testando Metarhizium anisoplae e Beauveria basiana $\left(10^{8}\right.$ conídios $\left./ \mathrm{mL}\right)$ em ovos, larvas e fêmeas ingurgitadas de $B$. microplus, observou elevada mortalidade em todos os estágios evolutivos.

Quando analisados estatisticamente, observou-se o efeito deletério dos fungos entomopatogênicos $S$. insectorum e $P$. fumosoroseus sobre a eclodibilidade dos ovos dos grupos das partenóginas tratadas e respectivos percentuais de eficácia $(P<0,05)$. A concentração de $10^{8}$ conídios $/ \mathrm{mL}$ foi melhor para o fungo $S$. insectorum, apresentando $82,99 \%$ de eficácia, enquanto que as outras concentrações $\left(10^{5}, 10^{6}, 10^{7}, 10^{9}\right.$ conídios $\left./ \mathrm{mL}\right)$ apresentaram eficácia de 27,93\%, 17,14\%, 50,26\%, $68,44 \%$, respectivamente. Esta ação deletéria, do referido fungo, pode ser visualizada na Figura $1 \mathrm{~A}$, onde se observa uma completa colonização da partenógina.

Para o fungo $P$. fumosoroseus, a melhor eficácia, em partenóginas, foi alcançada na concentração de $10^{9}$ conídios $/ \mathrm{mL}$, que apresentou valor de $82,93 \%$, enquanto que as concentrações de $10^{5}, 10^{6}, 10^{7}, 10^{8}$ conídios/ $\mathrm{mL}$ apresentaram eficácia de 13,21\%, 6,49\%, 43,40\%, $66,26 \%$, respectivamente. A colonização da partenógina, pelo fungo, desencadeando uma lesão no tegumento, pode ser verificada na Figura $1 \mathrm{~B}$ - seta.

Esses dados contrastam com os resultados de Barc et al. (1999), para Metarhizium anisoplae, os quais demonstraram que tal fungo apresentou $40 \%$ de eficácia sobre fêmeas ingurgitadas de $B$. microplus, na concentração de $10^{8}$ conídios $/ \mathrm{mL}$. Os autores concluem que o referido fungo, na concentração empregada, foi insuficiente no controle do ixodídeo em questão.

Os resultados de eclodibilidade e o percentual de redução de eclodibilidade dos ovos tratados com suspensões do $S$. insectorum e $P$. fumosoroseus, nas mesmas concentrações, são bastante divergentes entre si. O melhor percentual de redução de eclodibilidade significativa $(P<0,05)(79,04 \%)$ foi apresentado pelo $P$.

Tabela 1 - Eficácia dos fungos Sporothrix e Paecilomyces fumosoroseus sobre partenóginas (Boophilus microplus), percentagens de redução de eclodibilidade dos ovos tratados, percentagens de mortalidade de larvas tratadas e suas respectivas comparações múltiplas (teste de Tukey) das médias.

\begin{tabular}{|c|c|c|c|c|c|c|}
\hline \multirow{2}{*}{$\begin{array}{l}\text { Tratamentos } \\
\text { (conídios } / \mathrm{mL} \text { ) }\end{array}$} & \multicolumn{2}{|c|}{ Eficácia (\%) } & \multicolumn{2}{|c|}{ Redução de Eclodibilidade (\%) } & \multicolumn{2}{|c|}{ Mortalidade das Larvas (\% de Eficácia) } \\
\hline & S. insectorum & P. fumosoroseus & S. insectorum & P. fumosoroseus & S. insectorum & P. fumosoroseus \\
\hline Controle & - & - & - & - & - & - \\
\hline $10^{5}$ & $27,93^{\mathrm{ab}}$ & $13,21^{\mathrm{ab}}$ & $10,12^{a}$ & $37,5^{\mathrm{abc}}$ & $88,46^{\mathrm{b}}$ & $38,46^{a b}$ \\
\hline $10^{6}$ & $17,14^{\mathrm{ab}}$ & $6,43^{\mathrm{ab}}$ & $20,62^{a b}$ & $79,04^{d}$ & $46,15^{\mathrm{ab}}$ & $26,92^{a b}$ \\
\hline $10^{7}$ & $50,26^{a b c}$ & $43,4^{\mathrm{ab}}$ & $37,92^{a b c}$ & $65,79^{c d}$ & $65,38^{\mathrm{ab}}$ & $53,85^{\mathrm{ab}}$ \\
\hline $10^{8}$ & $82,99^{\mathrm{c}}$ & $66,26^{\mathrm{b}}$ & $17,68^{\mathrm{ab}}$ & $54,31^{\mathrm{bcd}}$ & $61,54^{\mathrm{ab}}$ & $84,62^{b}$ \\
\hline $10^{9}$ & $68,44^{\mathrm{bc}}$ & $82,93^{\mathrm{ab}}$ & $25,08^{a b}$ & $54,46^{\mathrm{bcd}}$ & $42,31^{\mathrm{ab}}$ & $69,23^{\mathrm{ab}}$ \\
\hline
\end{tabular}

\footnotetext{
* As comparações múltiplas da Eficácias são calculadas sobre redução de postura e eclodibilidade dos ovos das partenóginas tratadas.

** Na comparações múltiplas, todos os controles são identificados por ${ }^{\text {a }}$

*** $P<0,05$
}

\footnotetext{
* - valor estimado do número de larvras oriunda de $1 \mathrm{~g}$ de ovos de Boophilus microplus
} 
fumosoroseus na concentração de $10^{6}$ conídios $/ \mathrm{mL}$. Nas outras concentrações $\left(10^{5}, 10^{7}, 10^{8}, 10^{9}\right.$ conídios $\left./ \mathrm{mL}\right)$ não houve diferença significativa $(P>0,05)$ nos percentuais de redução de eclodibilidade $(37,50 \%, 65,79 \%$, $54,36 \%, 54,46 \%)$. Na Figura 1 D observa-se ovo parasitado pelo fungo e alterações sobre a camada externa, provavelmente causadas por enzimas.

O fungo S. insectorum apresentou melhor percentual de redução de eclodibilidade $(37,92 \%)$, estatisticamente significativa $(P<0,05)$, na concentração de $10^{7}$ conídios/ $\mathrm{mL}$ (Fig. $1 \mathrm{C}$ ), enquanto que nos outros tratamentos, os resultados obtidos foram de 10,12\%, 20,62\%, 17,68\%, $25,08 \%$, para as respectivas concentrações de $10^{5}, 10^{6}$, $10^{8}, 10^{9}$ conídios/mL.

Em experimento conduzido por Fernadez et al. (2001), não foi encontrada diferença estatística sobre o percentual de eclosão de larvas de $B$. microplus oriundas de ovos tratados com diferentes isolados de $B$.

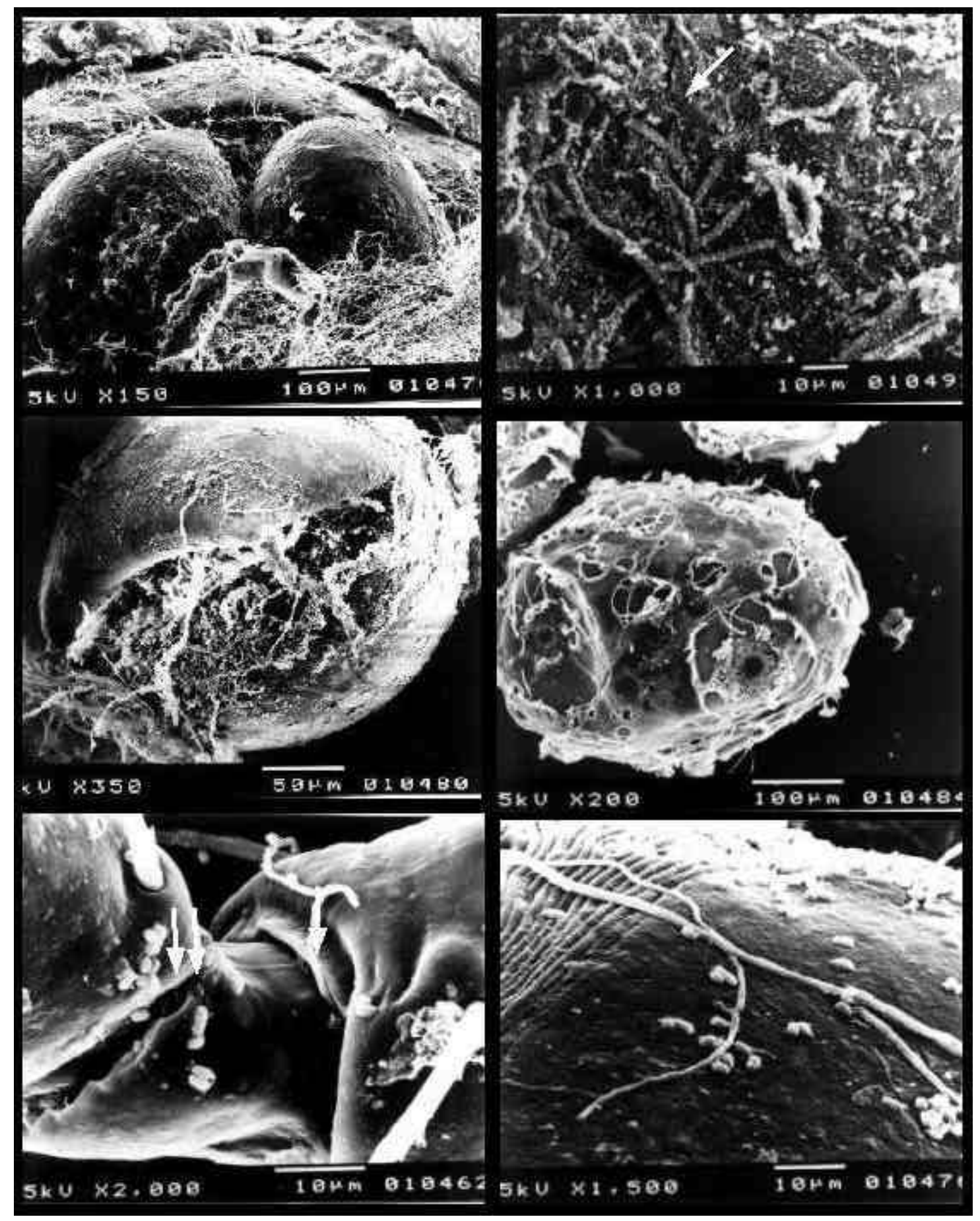

Figura 1 - Elétron-micrografias de varredura: A) Região labial da partenógina de Boophilus microplus predadas por Sporothrix insectorum, colonizada pelo fungo. B) Partenógina de B. microplus.predado por Paecilomyces fumosoroseus, detalhe do tegumento colonizado pelo fungo, com rupturas $(\downarrow)$. C) Ovo de B. microplus predado por $S$. insectorum, rompimento da cutícula externa, e habitado por hifas. D) Ovo de B. microplus predado por $P$. fumosoroseus, detalhe do ovo com rupturas na camada externa (hifas sob a camada). E) Larva de B. microplus predado por S. insectorum, detalhe da hifas penetrando no interior da articulação ( $\downarrow$ ) e conídios aderidos ao trocanter $(\downarrow \downarrow)$. F) Hifas e coníodios do fungo $P$. fumosoroseus colonizando a região dorsal da larva de $B$. microplus. 
bassiana, comparado ao grupo controle. Os autores apenas ressaltam que foi bastante inferior.

As larvas de B. microplus tratadas com suspensões de conídios dos fungos $S$. insectorum e $P$. fumosoroseus, não apresentaram diferenças estatísticas na mortalidade ( $P>0,05)$, quando comparadas ao controle nas diferentes concentrações $10^{5}, 10^{6}, 10^{7}, 10^{8}, 10^{9}$ conídios $/ \mathrm{mL}$, de ambos os fungos. Observações mostraram que as larvas tratadas apresentaram uma diminuição de movimentos dos seus membros posteriores, ficando evidente sua ação prejudicial sobre a deambulação das referidas larvas (Fig.1 E e 1F).

\section{Conclusões}

Com base nos resultados apresentados nesta pesquisa, pode-se inferir:

a) Sporothrix insectorum e Paecilomyces fumosoroseus apresentaram ação deletéria sobre partenóginas de $B$. Microplus, in vitro.

b) S. insectorum apresentou $82,99 \%$ de eficácia no controle das partenóginas, em suspensões de $10^{8}$ conídios/mL, enquanto $P$. fumosoroseus alcançou $82,93 \%$, em suspensão de $10^{9}$ conídios $/ \mathrm{mL}$.

c) $P$. fumosoroseus proporcionou uma maior redução da eclodibilidade de ovos de B. microplus (79,04\%) do que $S$. insectorum $(37,92 \%)$, quando utilizadas suspensões de $10^{6}$ conídios $/ \mathrm{mL}$ e $10^{7}$ conídios $/ \mathrm{mL}$, respectivamente.

d) A eficácia dos fungos sobre larvas de $B$. microplus foi de $84,62 \%$ e $88,46 \%$ ( $P$. fumosoroseus e $S$. insectorum) nas suspensões de $10^{8}$ e $10^{5}$ conídios/ $\mathrm{mL}$, respectivamente.

e) A microscopia eletrônica de varredura ilustra a ação dos fungos $S$. insectorum e $P$. fumosoroseus sobre os diferentes instares do B. microplus.

Portanto, com base nos resultados obtidos, podese inferir que os fungos Sporothrix insectorum e Paecilomyces fumosoroseus, apresentaram ação deletéria in vitro sobre as diferentes fases do ciclo do $B$. microplus. O emprego desses fungos como agentes de biocontrole pode ser uma alternativa promissora no combate deste importante ácaro.

\section{Referências Bibliográficas}

ALVES, S. B.; ALMEIDA, J. E. M.; MOINO JUNIOR, A.; ALVES, L. F. A. Técnicas de laboratório. In: Controle microbiano de insetos. 2. ed. Piracicaba: FEALQ, 1998. p. 637-710.

ALVES, S. B.; VIEIRA, S.A.; SILVEIRA NETO, S. Patogenicidade de Beauveria bassiana e Metarhizium anisopliae para ovos do carrapato Boophilus microplus. In: CONGRESSO BRASILEIRO DE ENTOMOLOGIA, 24, 1993, Piracicaba. Resumos... Piracicaba [s.n.], 1993. p. 344.

BARC, L. A. G.; ALMEIDA, J E. M.; CORRÊA, R. R. Avaliação da eficácia do fungo Metarhizium anisopliae isolado $C B$
103 sobre fêmea de B. microplus. In: SEMINÁRIO BRASILEIRO DE PARASITOLOGIA VETERINÁRIA, 11, 1999, Salvador. Resumos... Salvador: CBPV, 1999. p. 73-74.

BARROS, A. T. M.; EVANS, D. E. Ação de gramíneas forrageiras em larvas infestantes do carrapato dos bovinos, Boophilus microplus. Pesquisa Veterinária Brasileira ${ }_{2}$ Rio de Janeiro, v.9, n. 1-2, p. 17, 1989.

BITTENCOURT, V. R. E. P. Ação do fungo Metarhizium anisophiae (Metschnikoff, 1879) Sorokin, 1883, sobre o carrapato Boophilus microplus (Canestrini,1887). 1992. 105f. Tese ( Doutorado), Universidade Federal Rural do Rio de Janeiro, Rio de Janeiro, 1992.

CARLIE, M. J.; WATKINSON, S. C. The fungi. London: Academic Press, 1994. p. 355-360.

DRUMOND, R.O.; CRUST, S.F.; TREVINO, J.L.; GLADNEY, W.J.; GRAHAM, O.H. Boophilus annulatus and Boophilus microplus: laboratory tests of inseticides. Journal Economic Entomology., College Park, v.66, p. 130-133, 1973.

FERNANDES, É. K. K.; DA COSTA, G. L.; BITTENCOURT, V. R. E. P. Patogenicidade de diferentes linhagens de Beauveria bassiana (Bals) Vuill. em ovos de Boophilus microplus in vitro. In: SIMPÓSIO DE CONTROLE BIOLÓGICO, 7, 2001, Poços de Caldas. Resumos... Poços de Caldas [s.n.], 2001. p. 353.

GIRALDO, M.; LEGUIZAMOM, J.E. Biological control of Meloidogyne spp. Goeldi with the fungus Paecilocymes $s p$. Samson. in Luffa plants. Fitopatologia Colombiana, v.20, n.1-2, p. 20-25, 1996.

GONZALES, J. C.; MUNIZ, R. A.; FARIAS, A.; GOLÇALVES, L. C. B.; REW, R. S. Therapeutic and persistent efficacy of doramectin against Boophilus microplus in cattle. Veterinary Parasitology., v.49, Amsterdam, p. 107-119, 1993.

HORN, S. C. Prováveis prejuízos causados pelos carrapatos. Boletim Defesa Sanitária Animal., Brasília, v.17, 1983.

MAIA, A. S.; SANTOS, J. M. dos. A SEM technique for preparing biological control agentes of nematodes in action. Acta Microscopica, Caracas, v.6, Supple., B, p. 550551, 1997.

ORDONEZ, G.; DAVID, H. Sporothrix insectorum: Biological control method of lace bug leptopharsa gibbicarina in oil palm culture in latin America. (Hemiptera, Tingidae). Bulletin de la Societe Entomologique de France, ${ }_{2}$ Paris, v.98, n. 1. p. $77-85,1993$.

PENNA, V. M. Boophilus microplus: A resistência genética do hospedeiro como forma de controle. Cadernos Técnicos de Veterinária da Universidade Federal de Minas Gerais, Belo Horizonte, v.4, p. 3-65, 1990.

ROCHA, U. F. Biologia e controle biológico do carrapato Boophilus microplus. (CANESTRINI,1887). Jaboticabal: FCAV, 1984. 32 p. (Boletim Técnico).

SAS INSTITUTE. User's guide: statistics. Cary: 1998.

VERRÍSSIMO,C.J. Estudo da resistência e susceptibilidade do carrapato bovino (Boophilus microplus) em rebanho mestiço, 1990. 163f. Dissertação (Mestrado em Zootecnia) - Faculdade de Ciências Agrárias e Veterinárias, Universidade Estadual Paulista, Jaboticabal, 1990. 